\title{
Theoretical and experimental approach on laser cleaning of coins
}

\author{
N. Antonopoulou-Athera ${ }^{1}$ - C. Kalathakis ${ }^{2} \cdot$ E. Chatzitheodoridis $^{1} \cdot$ A. A. Serafetinides ${ }^{3}$
}

(c) Springer Nature Switzerland AG 2019

\begin{abstract}
Laser-based techniques are used more and more frequently for the cleaning of artifacts. Due to the different behavior of each material, when it is irradiated, studies and experiments are performed in order to find the optimum laser parameters for each case. In this work, the laser cleaning of coins is examined. Coins are studied with analytical methods in order to detect the corrosion products and the accretions. This information along with the composition of the coins' alloys is fed into an in-house developed program which estimates the penetration depth of the laser beam as well as the laser fluence for which the alloy starts to melt. Exploiting this information, laser cleaning of coins is performed with various conditions and parameters. Finally, the result is evaluated by using microscopic methods. From this research, it was found that the laser cleaning of copper, silver and aluminum alloys is feasible with Q-switched Nd:YAG at $1064 \mathrm{~nm}$. Also, higher level of corrosion and accretions requires higher laser intensity. For low corrosion level on copper alloys, a thin water film on the irradiated area is beneficial.
\end{abstract}

Keywords Coins' conservation · Q-switched Nd:YAG · Photothermal effects · Scanning electron microscopy-energy dispersive spectroscopy

\section{Introduction}

Most of the contemporary lasers are easy to use and fully parameterized through computer interfaces, offering promising results when used as a cleaning tool of artifacts with cultural value [1-4]. Laser cleaning of cultural heritage objects is not new and already has many practical applications. However, the large variety of materials used to fabricate the available cultural artifacts is not fully covered, allowing significant space for further investigations. Often still, it leads to novel findings, further extending the potential of laser in cleaning those objects.

This research focuses on evaluating cleaning procedures of metallic coins by an Nd:YAG laser irradiating with $1064 \mathrm{~nm}$. Laser cleaning tests on coins have already been performed with either promising [5-7] or forbidding results $[7,8]$. Abdel-Kareem et al. [5] used a Q-switched
$\mathrm{Nd}$ :YAG laser, at $1064 \mathrm{~nm}$ with pulse duration $5 \mathrm{~ns}$, for the cleaning treatment of silver-copper coins with a fluence of $1.6 \mathrm{~J} / \mathrm{cm}^{2}$, while the number of pulses was depending on the thickness of the corrosion layer. The researchers suggest the suitability of this laser system. Zhu et al. [6] also observed promising results on the cleaning treatment of copper coins with a Q-switched Nd:YAG laser, again at $1064 \mathrm{~nm}$ with a pulse duration of $8 \mathrm{~ns}$. For dry laser cleaning of copper alloys, the researchers suggest fluences at the range of $0.8-1 \mathrm{~J} / \mathrm{cm}^{2}$. Drakaki et al. [7] evaluated the effects of various laser systems, using different wavelengths and with pulse durations ranging from $\mu$ s to $\mathrm{ns}$, on silver-based and copper-based coins. The most promising results came from a long pulse (LP) Nd:YAG laser, at $1064 \mathrm{~nm}$, with fluence $0.55 \mathrm{~J} / \mathrm{cm}^{2}$ on the silver-based coins, while the free running (FR) Nd:YAG laser, at $1064 \mathrm{~nm}$, induced thermal effects in most of the cases. Korenberg

$\triangle$ N. Antonopoulou-Athera, n.athera@hotmail.com | ${ }^{1}$ School of Mining and Metallurgical Engineering, National Technical University of Athens, Heroon Polytechniou 9, 15780 Athens, Greece. ${ }^{2}$ School of Mechanical Engineering, National Technical University of Athens, Heroon Polytechniou 9, 15780 Athens, Greece. ${ }^{3}$ Physics Department, National Technical University of Athens, Heroon Polytechniou 9, 15780 Athens, Greece. 
and Baldwin [8] used an Nd:YAG laser at $1064 \mathrm{~nm}$, with pulse duration $5-10 \mathrm{~ns}$ and fluences $0.4-0.9 \mathrm{~J} / \mathrm{cm}^{2}$, for the cleaning of copper-based coins. The researchers concluded that this laser cleaning treatment is not suitable for copper coins.

The selected laser parameters and the conclusions from the various researchers show that there has not been yet defined a standard protocol for the laser cleaning treatment of coins, even though the results seem promising in several cases. In this study, we aim to reexamine safe laser cleaning parameters on coins with various chemical compositions, which can possibly be applied on other metallic artifacts as well. Laser systems are being tested the last decades for the cleaning treatment of metallic artifacts because of the advantages that can offer against the conventional cleaning treatments. A laser system can provide effectiveness, selectivity and layer-by-layer ablation, and it is fast and reduces costs. On the other hand, it is still not widely used because of some unwanted effects from the interaction of the laser with the material, mostly due to photothermal effects that cause a direct temperature increase in the metals. Getting over this obstacle, laser cleaning could potentially find a wider usage relative to conventional methods, which still have some disadvantages. For example, mechanical cleaning leaves scratches on the metal's surface, while chemical and electrochemical cleaning can possibly lead to secondary contamination. Both are still not easily controllable cleaning methods $[6$, $9,10]$.

Every material reacts differently, when it is irradiated by a laser system, mainly due to its different optical and thermal properties. This is especially true for metals and alloys, i.e., coins; therefore, this research attempts to investigate the effect of thermal phenomena arising from the interaction of alloy materials with the laser light. Furthermore, the optimum laser parameters should be identified and experimentally tested prior to any cleaning process in a regular basis.

The assessment of the effectiveness of a certain technique in any different case is absolutely crucial. Thus, the condition of each cultural object is evaluated prior and after cleaning with the laser, using a variety of diagnostic methods. The uniqueness of each material leads to the necessity of a "cleaning protocol" that employs the optimum laser parameters in each case. This can lead to a set of conditions archived in database and recalled on demand, which might also include software algorithms which further optimize the cleaning process resulting in semi-autonomous cleaning systems.

The characterization and analysis techniques used to estimate the optimum conditions for the materials studied here include mainly the X-ray diffraction (XRD) technique and the Raman spectroscopy. With these methods, the corrosion products and accretions of foreign materials on the surfaces of the objects were easily identified. Optical microscopy (OM) and scanning electron microscopy combined with energy-dispersive $X$-ray spectroscopy (SEM-EDS) were also used for the evaluation of the cleaning process.

\section{Materials and methods}

\subsection{Materials and laser cleaning}

The cleaning procedure was accomplished in normal atmospheric conditions, with the aid of a nanosecond Q-switched Nd:YAG laser working at $1064 \mathrm{~nm}$, with a pulse duration of $6 \mathrm{~ns}$, and pulse frequency that can be adjusted from 1 to $20 \mathrm{~Hz}$, while the output energy was adjusted at $23.5 \mathrm{~mJ}$ and $82.4 \mathrm{~mJ}$ (average value of multiple measurements). This wavelength was preferred after preliminary experiments that were performed using both UV and near IR on over 20 coins [11]. All these experiments indicated that the $1064 \mathrm{~nm}$ laser pulse succeeded to clean metal coins; the only drawback comes from photothermal effects, which could be avoided only with the use of low fluences. This is also demonstrated in the literature [12-15].

Apart from the laser, the instrumental setup used in this study is equipped with a focusing lens (focal length of $100 \mathrm{~mm}$ ) and an xy stage controlled by stepper motors with velocity set to $0.8 \mathrm{~cm} / \mathrm{s}$. These translate the sample horizontally along the two directions. Prior to any cleaning procedure, a third translational stage was positioning the focus lens and leaving it steady at certain distances in order to control the spot size on the sample, that is the irradiated area and consequently the laser fluence. In all cases, the sample was positioned at a distance between the lens and the actual focusing point of this lens, which is at a distance smaller than $10 \mathrm{~cm}$, i.e., $2 \mathrm{~cm}$ to achieve a spot diameter of $1 \mathrm{~cm}$, and at $8.5 \mathrm{~cm}$ to achieve a spot diameter of $0.25 \mathrm{~cm}$. The system is controlled by an in-house built software program, which also controls the laser. Prior to each analysis, the energy of the pulses was measured with a pyroelectric energy meter. This configuration, namely the movement of the sample accompanied with a pulsed laser system, performs as a quasi-continuous laser beam system.

The set of samples is comprised of five coins, which are composed of different alloys (Table 1). The aim was to optimize their cleaning treatment and material damage by conducting laser cleaning experiments, especially with the use of a computer code developed with MATLAB, which computes the heat transfer from the laser beam to the material. 
Table 1 List of coins

\begin{tabular}{lllllc}
\hline Sample name & Coin ID [16] & $\begin{array}{l}\text { Circulation } \\
\text { (year/country) }\end{array}$ & $\begin{array}{l}\text { Reference concen- } \\
\text { tration (wt \%) [16] }\end{array}$ & $\begin{array}{l}\text { Reference } \\
\text { weight (g) [16] }\end{array}$ & $\begin{array}{l}\text { Weight of cor- } \\
\text { roded coins (g) }\end{array}$ \\
\hline 10_Dk & KM\#78 & 1966/Greece & $95 \mathrm{Al}, 5 \mathrm{Mg}$ & 1.0 & 1.03 \\
2_DR & KM\#151 & $1990 /$ Greece & $99 \mathrm{Cu}, 1 \mathrm{P}$ & 3.8 & 3.78 \\
5_CT & KM\#933 & $1970 /$ France & $92 \mathrm{Cu}, 6 \mathrm{Al}, 2 \mathrm{Ni}$ & 2.0 & 1.95 \\
10_DR & KM\#132 & $1982 /$ Greece & $75 \mathrm{Cu}, 25 \mathrm{Ni}$ & 7.6 & 7.46 \\
30_DR & KM\#87 & $1964 / G r e e c e$ & $83.5 \mathrm{Ag}, 16.5 \mathrm{Cu}$ & 12 & 11.95 \\
\hline
\end{tabular}

\subsection{Diagnostic methods}

A Wild M8 stereomicroscope (School of Mining and Metallurgical Engineering, National Technical University of Athens, Greece) was used for the direct evaluation of the laser cleaning. The images were captured by a commercial highresolution camera with an adapter, which was positioned at the eyepiece tube of the stereomicroscope.

Micron-scale topographical investigation for the assessment of the cleaning treatment was performed with the set of a SEM analytical instrument, a JEOL 6380LV (School of Mining and Metallurgical Engineering, National Technical University of Athens, Greece), operating at $20 \mathrm{kV}$ (primary electron beam), with $82 \mathrm{~mA}$ filament current and using high vacuum in the sample chamber. Metal is already a conductor, and therefore, the samples do not require coating with a conducting material. However, a carbon-based conducting adhesive film was used to stabilize the objects on the sample holder allowing electric discharge of the samples during analysis. The electron microscope is equipped with an EDS system from Oxford Instruments, with a silicon drift detector (SDD) and the INCA software. This was used for the chemical analyses of both the chemistry of the coins, their corrosion products and the adhered burial residues.

A Bruker D8 focus (School of Mining and Metallurgical Engineering, National Technical University of Athens, Greece) was used for the mineral identification of the corrosion products and the burial residues. The XRD diagrams were collected with the $2 \theta$ angle ranging from $3^{\circ}$ to $75^{\circ}$ and with an angle step resolution of $0.020^{\circ}$. The integration time was set to $1 \mathrm{~s} / \mathrm{step}$.

A Renishaw RM1000 microRaman spectrometer (School of Mining and Metallurgical Engineering, National Technical University of Athens, Greece) operating at $633 \mathrm{~nm}$ has been used for the phase identification of the corrosion products of the coins. The setup of the Raman spectrometer is constituted by an optical polarizing confocal microscope and a spectrometer. The entrance slit to the spectrometer is set to $40 \mu \mathrm{m}$ wide, while the spectrometer's grating has 1800 lines/ $\mathrm{mm}$. Signal is acquired with a Peltier-cooled CCD camera controlled by the Renishaw's Wire software version 1.3 and the Grams32 acquisition software. The optical microscope of the Raman system was operated in reflected light mode.

\section{Results and discussion}

The coins were analyzed prior to any treatment in order to identify the possible minerals and corrosion products covering the alloys. Raman was employed whenever XRD was not capable of detecting the accretions and the corrosion products, mainly due to the small amount of the mineral phases. For the 10_DK, the detected calcite and anorthite are part of the soil's accretions, unevenly distributed on the surface of the coin, while the indication of aluminum oxide is either due to the accretions or due to the passive film [17], which covers the aluminum matrix, in order to protect the latest from corrosion (Fig. 1). For copper-based coins (2_DR, 5_CT and 10_DR), cuprite is the main corrosion product, which was identified by both XRD and Raman (Figs. 1 and 2). The mineral phases on the coin 5_CT were not identified by XRD, while Raman identified the band of cuprite at $203 \mathrm{~cm}^{-1}$ [18]. Silver sulfide (mineral acanthite) constitutes the tarnish of silver on the coin 30_DR, and it was identified by Raman with bands up to $300 \mathrm{~cm}^{-1}$; the bands at 487 and $1438 \mathrm{~cm}^{-1}$ are possibly due to photo-decomposition products of the silver sulfide [19] (Fig. 2).

The chemical substance of the layer, usually a thin film, which covers the alloy's matrix, was also incorporated in the software program that was developed to estimate the minimum fluence from which the melting process of the alloys begins. For the aluminum alloy (coin 10_Dk), the passive film of aluminum oxide was employed due to its possible existence according to the XRD analysis (Fig. 1, 10_Dk). In this coin, there was not any indication of a corrosion product at the analyses, solely minerals from its burial environment. For the copper alloys, the main corrosion product that of cuprite was used, as well as for the silver alloy with the corrosion product of the silver sulfide. 


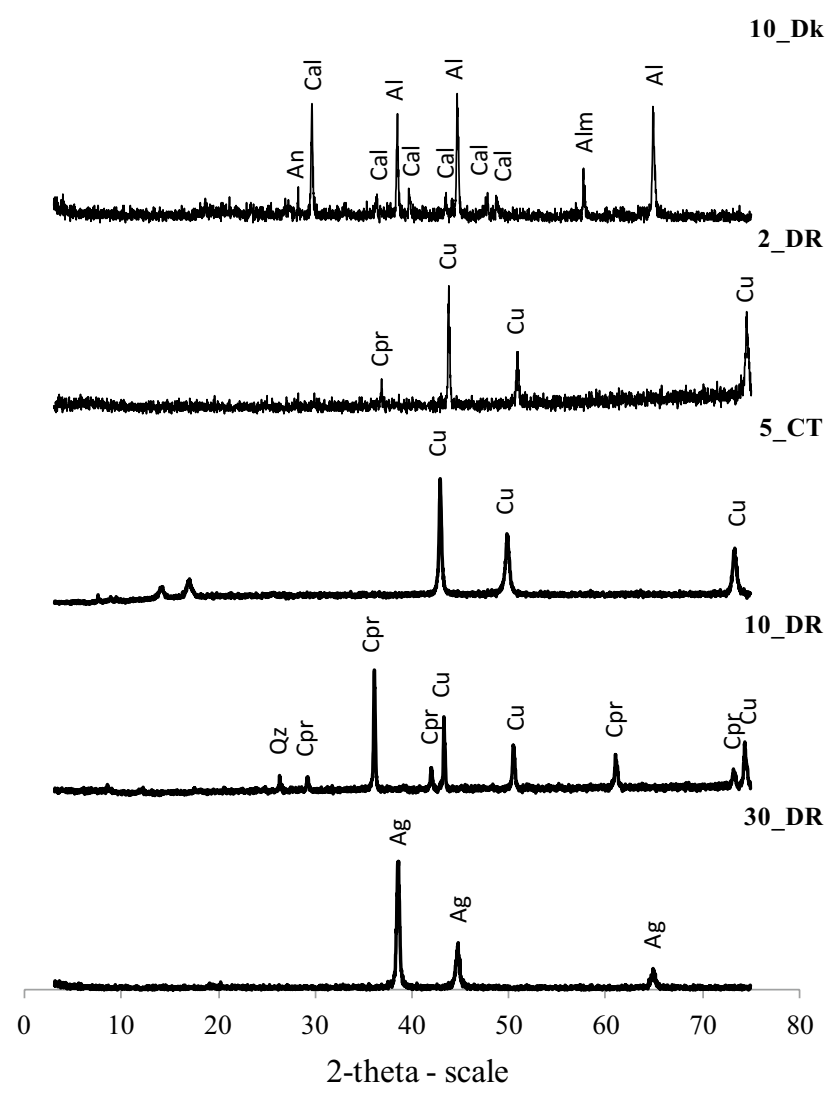

Fig. 1 XRD diagrams of the five corroded coins. (An anorthite, $\mathrm{Cal}$ calcite, $A l$ aluminum-metal, $A l m$ aluminum oxide, $\mathrm{Cpr}$ cuprite, $\mathrm{Cu}$ copper-metal, Qz quartz, Ag silver-metal)

\subsection{Theoretical approach for laser fluence estimation}

The theoretical approach for the fluence estimation during laser irradiation is based on the heat transfer from the laser pulse to the surface of the sample [15, 20-23]. The coins are composed of the alloy (main matrix), possibly a passive film in some cases, in order to protect the main matrix from corrosion, the corrosion products (a surface alteration zone) and the accretions (adhered foreign material on the surface of the coins). In order to computationally estimate the fluence that causes the melting of the alloy's matrix, it was necessary to include in the calculation the optical properties of the passive film for aluminum alloy and the respective corrosion products for the copper and silver alloys, as well as the lowest melting temperature between the alloy and its covering layer [24].

For the estimation of fluence, the analysis of Sands [21] is followed. The heat equation is based on the Fourier's law for thermal conduction (Eq. 1). The heat $(Q)$ that is stored in a material is assigned to the enthalpy per volume unit $\left(H_{v}\right)$ (Eq. 2). The energy that is introduced into a small volume of a material will be either released unchanged or it will change the enthalpy of the material (Eq. 3). The negative divergence depicts the heating of the material. During laser irradiation, there is an additional energy source, the intensity of the light (I) will be absorbed by the sample [20], which is estimated according to the Beer-Lambert law (Eq. 4). Consequently, Eq. (3) takes the form of Eq. (5) and the tensor analysis leads to Eq. (6). Assuming that the radial heat transfer is negligible, the examination only for the $z$ axis (depth) leads to Eq. (7). Blackwell et al. [20] concludes that a simplified version of the equation (Eq. 8) is also valid when the result of the multiplication of the thermal diffusivity $(\delta)$ with pulse duration $\left(t_{\mathrm{p}}\right)$ is much smaller than $1\left(\delta t_{\mathrm{p}} \ll 1\right)$, which is valid for a $6 \mathrm{~ns}$ pulse. This assumption is based on the fact that all the amount of the energy is absorbed very locally in a tiny volume of the material and it is consumed by increasing its internal energy. The thermal diffusivity can be then computed by the equation $\delta=k /\left(\rho C_{\mathrm{p}}\right)$, where $k$ is the thermal conductivity, $\rho$ is the density of the material and $C_{p}$ is the heat capacity. Moreover, it is assumed that the value of the thermal conductivity did not change in the material for the certain thermal penetration depth, due to the minimum amount of time of each laser pulse. Thus, the first and the second terms at
5_CT

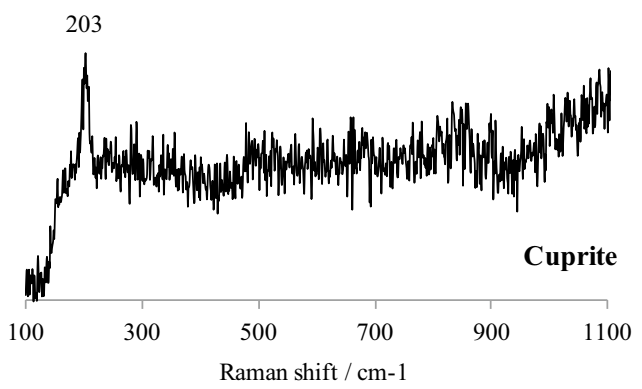

30_DR

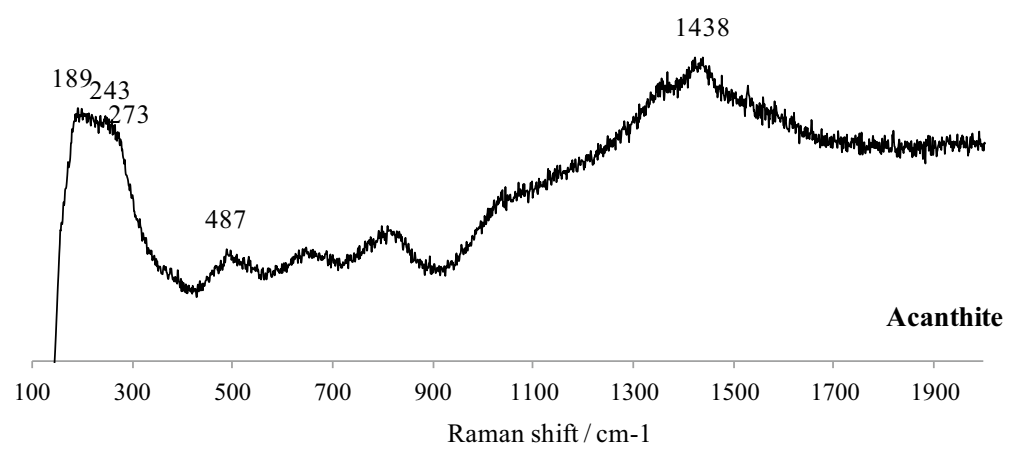

Fig. 2 Raman spectra of the corroded coins 5_CT and 30_DR 
the right-hand side of Eq. (7) are significantly negligible and can be omitted. In Eq. (8), the initial temperature of the material $\left(T_{0}\right)$ was set at room temperature.

$\frac{\mathrm{d} Q}{\mathrm{~d} t}=-k \nabla T$

$\Delta \mathrm{H}_{\mathrm{V}}=\rho C_{p} \Delta \mathrm{T}$

$\nabla \cdot \frac{\mathrm{d} Q}{\mathrm{~d} t}=-\frac{\mathrm{dH}}{\mathrm{d} t}$

$S(z)=a \mathrm{l}(z)=\alpha \mathrm{I}_{o}(1-R) \exp (-a z)$

$S(z)-\nabla \cdot \frac{\mathrm{d} Q}{\mathrm{~d} t}=\frac{\mathrm{dH}}{\mathrm{d} t}$

$S(z)+k \nabla^{2} T+\nabla k \cdot \nabla T=\frac{\rho C_{\mathrm{p}} \mathrm{d} T}{\mathrm{~d} t}$

$\frac{\mathrm{d} T}{\mathrm{~d} t}=\frac{k}{\rho C_{\mathrm{p}}} \frac{\partial^{2} T}{\partial z^{2}}+\frac{1}{\rho C_{\mathrm{p}}} \frac{\partial k}{\partial z} \frac{\partial T}{\partial z}+\frac{S(z)}{\rho C_{\mathrm{p}}}$

$\mathrm{T}-\mathrm{T}_{o} \approx \frac{\mathrm{I}_{o}(1-R) a}{\rho C_{\mathrm{p}}} \mathrm{e}^{(-a z)} t \quad \delta t \ll 1$

The optical and thermal constants are temperaturedependent, and they change during the increase in the temperature. The short time ( $6 \mathrm{~ns}$ pulse) that a temperature increase is induced allows the use of the constant values of the material at their relaxed state, as these apply at the state of the material prior to irradiation. Then, the melting fluence $\left(F_{\mathrm{m}}\right)$ of the material can be approximated.

It must be here mentioned that this algorithm applies only to the first pulse. Following pulses on the same spot should be on lower fluence according to the calculations. The fluence of each following pulse can be calculated using our computational model by inserting into the new calculation the calculated cumulative temperature that the sample has reached and the replacement of the temperature-dependent constants. This was precluded in our experiments by using single pulses on the same spot. However, in order to achieve a continuous cleaning treatment with a pulsed laser, overlapping of a part of the pulses is required and temperature accumulation should be calculated only for a small area of the irradiated spot of the sample. The easiest approach to avoid this complication is to leave adequate time for the sample to cool, an unnecessary complication since accretions and corrosion layers on naturally corroded samples are variables in thickness and affect the interaction with the energy of the laser beam. To further minimize the above complexity, masked expanded Gaussian beams can be used, forming an approximated flat-top profile on the sample. In this research, an approximation of a flat-top beam was achieved by the pulse overlapping, related to the result on the sample's surface, i.e., the uniformity of the energy allocation results to a uniform laser cleaning treatment.

The developed algorithm computes the heat transfer from the laser beam to material, and it is based on the aforementioned equations. The input is in the form of a MATLAB structure array (struct) with the values $\rho, k, C_{\mathrm{p}}, T_{\mathrm{m}}$ (melting temperature), $a$ (optical absorption coefficient), $R$ (surface's reflectance), $I_{\mathrm{o}}$ and $t_{\mathrm{p}}$ (Table 2 ). The developed algorithm produces two diagrams as a result (Fig. 3). The first diagram (left diagrams in Fig. 3) depicts the temperature (vertical axis) along the thermal penetration depth (horizontal axis) for the chosen fluence $\left(F_{\mathrm{o}}=l_{\mathrm{o}} t_{\mathrm{p}}\right)$. The second diagram (right diagrams in Fig. 3 ) depicts the same information but for the fluence for which the melting of the material starts. In order to compute the temperature change over time, five subdivisions of a pulse's duration are specified $\left(0 \mathrm{~s}\right.$-blue line, $t_{\mathrm{p}} / 32 \mathrm{~s}-\mathrm{cyan}$ line, $t_{\mathrm{p}} / 16 \mathrm{~s}-$ green line, $t_{\mathrm{p}} / 4 \mathrm{~s}$-yellow line and $t_{\mathrm{p}} \mathrm{s}$-red line).

The melting temperature of pure materials or the lowest temperature between the matrix and the layer, which is in touch with the matrix, for multilayered materials, was used to terminate the calculations, signified by the phase change of the matter. When the phase change starts, the used methodology is not any longer valid since the consumed energy does not result in the increase in the

Table 2 Physical and thermal constants of alloys, optical constants of their covering layer and laser parameters. (thermal conductivity [25, $26]$, heat capacity $[25,27-29]$, melting temperature [25, 30], absorption coefficient [31-33] and reflectivity [31, 32, 34])

\begin{tabular}{|c|c|c|c|c|c|c|c|c|c|}
\hline $\begin{array}{l}\text { Sample } \\
\text { name }\end{array}$ & $\begin{array}{l}\text { Alloy (1)/corro- } \\
\text { sion product ( } 2 \text { ) }\end{array}$ & $\begin{array}{l}\rho \\
\left(\mathrm{kg} \mathrm{m}^{-3}\right) \\
(1)\end{array}$ & $\begin{array}{l}\text { k } \\
\left(\mathrm{W} \mathrm{m}^{-1} \mathrm{~K}^{-1}\right) \\
(1)\end{array}$ & $\begin{array}{l}C_{p} \\
\left(\mathrm{~J} \mathrm{~kg}^{-1} \mathrm{~K}^{-1}\right) \\
(1)\end{array}$ & $\begin{array}{l}T_{\mathrm{m}} \\
(\mathrm{K})\end{array}$ & $\begin{array}{l}a \\
\left(\mathrm{~m}^{-1}\right) \\
(2)\end{array}$ & $\begin{array}{l}R \\
(2)\end{array}$ & $\begin{array}{l}I_{\mathrm{o}}\left(\mathrm{W} \mathrm{m}^{-2}\right) \\
\text { for } t_{\mathrm{p}}=6 \cdot 10^{-9}\end{array}$ & $\begin{array}{l}F_{\mathrm{m}} \\
\left(\mathrm{mJ} / \mathrm{cm}^{2}\right)\end{array}$ \\
\hline 10_Dk & AlMg $5 / \mathrm{Al}_{2} \mathrm{O}_{3}$ & 2663.3 & 127 & 963 & 873 & $1.08 \times 10^{8}$ & 0.95 & $1.65 \times 10^{11}$ & 27.4 \\
\hline 2_DR & $\mathrm{Cu} / \mathrm{Cu}_{2} \mathrm{O}$ & 8940 & 386 & 384.95 & 1356 & $1 \times 10^{6}$ & 0.21 & $2.73 \times 10^{11}$ & 460.9 \\
\hline 5_CT & $\mathrm{Cu} 92 \mathrm{Al} / \mathrm{Cu}_{2} \mathrm{O}$ & 8565.68 & 73 & 439 & 1330 & $1 \times 10^{6}$ & 0.21 & $2.16 \times 10^{11}$ & 491.2 \\
\hline 10_DR & $\mathrm{CuNi} 25 / \mathrm{Cu}_{2} \mathrm{O}$ & 8932 & 32 & 378 & 1508 & $1 \times 10^{6}$ & 0.21 & $5.78 \times 10^{11}$ & 517.1 \\
\hline 30_DR & $\mathrm{Ag} / \mathrm{Ag}_{2} \mathrm{~S}$ & 10,490 & 405 & 234.25 & 1098 & $1.77 \times 10^{6}$ & 0.23 & $0.78 \times 10^{11}$ & 144.2 \\
\hline
\end{tabular}



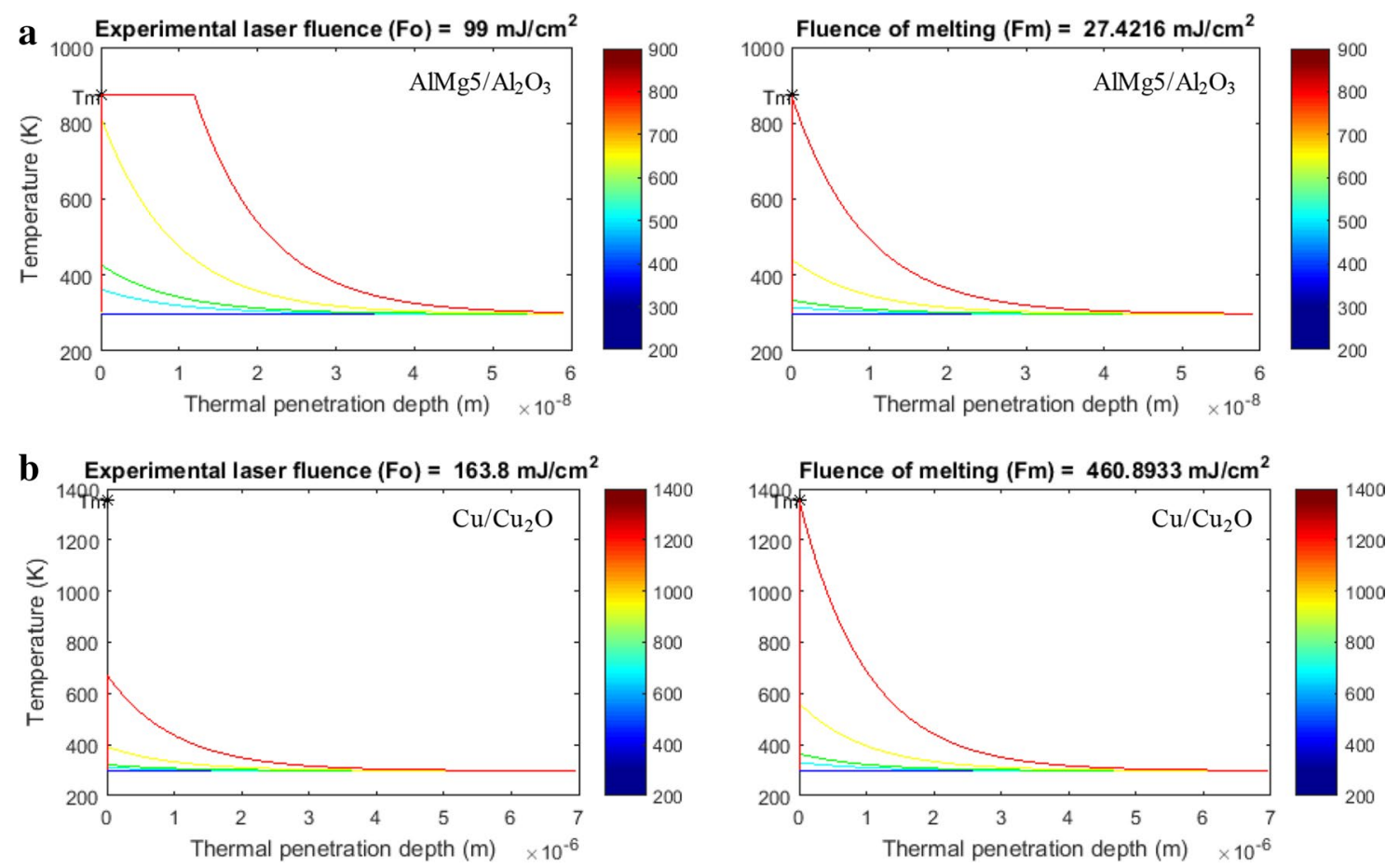

Fig. 3 Indicative temperature-depth diagrams of (a) $\mathrm{AIMg} 5 / \mathrm{Al}_{2} \mathrm{O}_{3}$ and (b) $\mathrm{Cu} / \mathrm{Cu}_{2} \mathrm{O}$ for five specified times $\left(0-\mathrm{t}_{\mathrm{p}} \mathrm{s}\right)$

temperature but rather for the phase change, which takes place at constant temperature.

\subsection{Experimental approach with QS Nd:YAG at $1064 \mathrm{~nm}$}

The experimental approach was dictated by the range of the fluences, for which the alloy's matrix is protected from melting and which were estimated by the MATLAB algorithm. In the cases where higher fluences were applied, the results were evaluated in order to assess the validity of the developed algorithm.

During the preliminary tests, it was found that laser cleaning by individual pulses created imprints on the surfaces, mostly due to the non-uniform energy allocation of the Gaussian beam. However, in quasi-continuous laser cleaning, almost uniform irradiation conditions were achieved by overlapping a part of each spot. The quasicontinuous laser cleaning was accomplished with the sample's movement during the laser firing.

The parameters and the conditions used to perform the experiments are summarized in Table 3. As it can be seen for almost all cases, the used fluence is lower than the computed one (Table 2) taking into account the expected overlapping, with the exceptions of 10_Dk and 10_DR, where the thickness of the accretions layers dictated the use of higher fluences in the initial cleaning cycles.

The aluminum alloy with a thin film of aluminum oxide on its surface melts at very low fluences according to the computed results $\left(27.4 \mathrm{~mJ} / \mathrm{cm}^{2}\right)$ (Fig. 3a). For the

Table 3 Experimental parameters for the laser cleaning treatment of the corroded alloys

\begin{tabular}{|c|c|c|c|c|}
\hline Sample's name & $\begin{array}{l}\text { Fluence } \\
\left(\mathrm{mJ} / \mathrm{cm}^{2}\right)\end{array}$ & $\begin{array}{l}\text { Repetition } \\
\text { rate }(\mathrm{Hz})\end{array}$ & Applied conditions & Cleaning performance \\
\hline 10_Dk & 99 & 4 & Dry & - \\
\hline 2_DR & 164 & 2 & Wet & Application of distilled water before every horizontal cleaning \\
\hline 5_CT & $\begin{array}{l}37 \\
130\end{array}$ & $\begin{array}{l}4 \\
4\end{array}$ & Dry & Energy alternation on each cleaning cycle \\
\hline 10_DR & $\begin{array}{l}145 \\
347 \\
1680\end{array}$ & $\begin{array}{l}4 \\
4 \\
\text { Pulsed }\end{array}$ & Dry/wet & $\begin{array}{l}\text { Spot's diameter alternation on each cleaning cycle. Application } \\
\text { of distilled water at the final cleaning cycle }\end{array}$ \\
\hline 30_DR & 47 & 4 & Dry & Use of a soft brush to wipe the $\mathrm{Ag}(\mathrm{s})$ after the cleaning treatment \\
\hline
\end{tabular}


case of the 10_Dk coin, the laser cleaning started with energy output of $23.5 \mathrm{~mJ}$ and the diameter of the beam spot was $1 \mathrm{~cm}$ at the surface of the sample. However, it was not possible to ablate the accretions layers with these parameters. The coverage by thick accretions of calcite and anorthite (Fig. 4a, b) has led to the increase in the applied fluence by decreasing the beam's spot size. Therefore, the focus lens was translated in order to achieve variable spot size, in this case to decrease the spot's diameter, while increasing the fluence until the accretions layers are removed. This was achieved with a spot diameter of $0.55 \mathrm{~cm}$ and fluence of $99 \mathrm{~mJ} / \mathrm{cm}^{2}$, exceeding the calculated value over the safe range of fluences. Still the calculated safe ranges apply and have been confirmed by irradiating areas with thinner accretions layers. To ensure these results, we inspected the cleaned sample both with optical and electron microscopy, there were not any thermal effects, often visible as systematically distributed bubbles or indentations (Fig. 4c, d). The procedure followed here is a good demonstration of a realistic case study with samples having variable thickness and composition of accretions layers, where spot size and consequently fluence, sample position and computed safe irradiation values are constantly estimated and evaluated by optical microscopy. This setup could be the basis of a commercial instrument performing semi-automated cleaning.
The melting of copper alloys was observed in preliminary tests at a range of fluences between 0.59 and $1.76 \mathrm{~J} /$ $\mathrm{cm}^{2}$, due to the photothermal effects caused at the wavelength of $1064 \mathrm{~nm}$. These findings are also in agreement with bibliography [35] and with the results acquired from the MATLAB algorithm, in which the melting starts approximately at $0.5 \mathrm{~J} / \mathrm{cm}^{2}$ (Table 2 ). These preliminary tests were used as a confirmation for the necessity to operate within the range of computed safe fluences, when the alloy of the coin has almost been revealed.

The cleaning procedure was restricted at low fluences in all the copper-based coins with the exception of the coin 10_DR, which was covered by a thick layer of corrosion products and soil accretions (Table 3). Furthermore, it was found that during the laser cleaning of copper-rich alloys, the surface may become black, an effect highly avoided by using a water film on the irradiated surface. Consequently, the coin 2_DR with Cu > 95 wt\% was successfully cleaned only with the application of a film of distilled water on the surface of the coin before every horizontal laser cleaning (Fig. 5a, b). The energy output was $82.4 \mathrm{~mJ}$, and the diameter of the spot was $0.8 \mathrm{~cm}$ resulting to a fluence of $164 \mathrm{~mJ} / \mathrm{cm}^{2}$. This low fluence did not induce photothermal effects (Fig. 5c, d). In this case, the developed algorithm suggested a larger range of safety fluences $\left(<460.9 \mathrm{~mJ} / \mathrm{cm}^{2}\right)$ for a single pulse. Intermediate fluences though ensure that no excess heating is deposited when
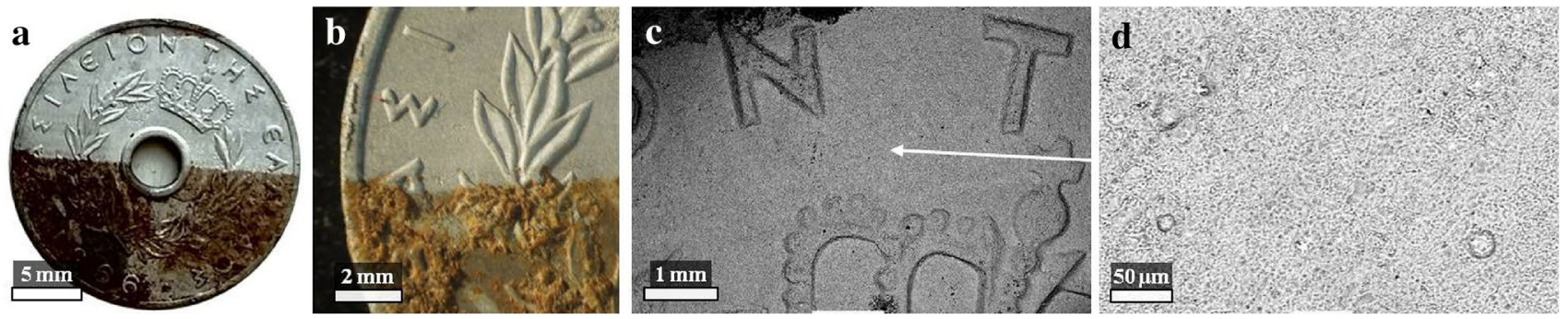

Fig. 4 Optical and electron images of the coin 10_Dk: a The upper half was laser cleaned, while the bottom half remains unclean, discerned by the dark brown soil's accretions. b OM image magnifica- tion showing the clean (above) and corroded (below) area. c SEM image on backscattered mode of the cleaned area. $\mathbf{d}$ SEM backscatter magnification of the cleaned area indicated by the arrow in $\mathbf{c}$
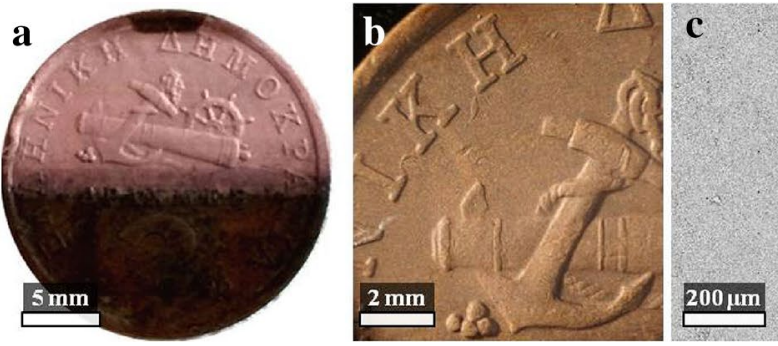

Fig. 5 Optical and electron images of the coin 2_DR: a The upper half of the coin was laser cleaned, while the bottom half remains corroded, and the depiction cannot easily be discerned. b OM image of the cleaned area. c Backscatter electron image of the cleaned area. $\mathbf{d}$ Magnification of an area of image $\mathbf{c}$ indicated with the white arrow 
overlapping spots have to be used. Two cleaning cycles were carried out with the same parameters and conditions. However, the laser cleaning evaluation (see paragraph 3.3) showed that for thin accretions and corrosion layers, it is beneficial to terminate the procedure after the end of the first cleaning cycle. The coin 5 CT with $85 w t \%>C u>95$ wt $\%$ was fully covered by thin layers of corrosion and accretions (Fig. 6a), and only small areas of the actual matrix could be accessed through this layer. Laser tests in alloys with similar concentrations indicated the need of a large spot size of the laser beam, in order to allocate the energy of the Gaussian laser beam at a larger area. Small spots' size left imprints even in the quasi-continuous cleaning, because of the increased fluence. In this case, energy was regulated by adjusting the applied voltage at the laser flashlamp (energy output $23.5 \mathrm{~mJ}$ and $82.4 \mathrm{~mJ}$ ). The diameter of the beam's spot was set at $0.9 \mathrm{~cm}$. The first cleaning treatment was performed in horizontal continuous irradiation mode with $130 \mathrm{~mJ} / \mathrm{cm}^{2}$, while a second cleaning step was performed with a fluence of $37 \mathrm{~mJ} / \mathrm{cm}^{2}$. Generally, in this type of alloys, mainly copper-aluminum alloys, even when the accretions and corrosion layers are thin, it was proven necessary to apply a last cleaning treatment with very low fluence and large spot size in order to achieve macroscopically a uniform final result. The clean areas were observed by OM (Fig. 6b) and SEM (Fig. 6c, d), in order to evaluate the laser cleaning performance. The thin layer of the corrosion products was ablated uniformly, letting the surface unaffected from the laser irradiation, even in high magnification (Fig. 6d).

The coin 10_DR was fully covered by corrosion products and accretions. Low fluences were incapable to ablate the accretions, and focused beam into narrow spot has been used to remove them (Fig. 7a). The energy of the laser beam was constant during this cleaning treatment $(82.4 \mathrm{~mJ})$. The diameter of the beam's spot $(0.85,0.55$ and 0.25 ) was varied by changing the distance of the laser focus lens from the sample $(3.5,6.5$ and 8.5 , respectively). The first cleaning cycle was performed using pulses with fluence of $1.68 \mathrm{~J} / \mathrm{cm}^{2}$ (spot's diameter of $0.25 \mathrm{~cm}$ ), with no spot overlapping, and then by a larger spot size (diameter of $0.55 \mathrm{~cm}$ ) and continuous cleaning (Fig. 7a). This cleaning cycle was repeated in order to fully remove the external corrosion and accretions. The next two cycles were achieved with lower fluences $\left(145 \mathrm{~mJ} / \mathrm{cm}^{2}, 347 \mathrm{~mJ} / \mathrm{cm}^{2}\right)$. At the end of the third cleaning cycle, the observation with OM suggests that a further cleaning step should be performed with even lower fluence (Fig. 7b). Thus, the final cleaning cycle was performed with a fluence of $145 \mathrm{~mJ} /$ $\mathrm{cm}^{2}$ and on wet sample surface (application of distilled water before the laser irradiation) (Fig. c, d). SEM observation of the clean areas with low magnification shows a uniform area (Fig. 7e), while in high magnification the texture due to the extended corrosion, which 10_DR was subjected to, is apparent (Fig. 7f).

The corrosion products of the silver-based coin 30_DR were directly interacting with the laser already at the low fluence of $47 \mathrm{~mJ} / \mathrm{cm}^{2}$. The thin layer of the silver sulfide, which has been identified by Raman, possibly interacts with the near-IR radiation and decomposes, producing again metallic silver (Ag(s)) (Fig. 8a) [19]. The metallic silver was wiped by a soft brush, in order not to burden the surface's topography mechanically (Fig. 8b, c). The observation, of the cleaned areas, with OM shows the metallic material free of corrosion and accretions (Fig. 8c). SEM observation shows that foreign substances (black spots) still remain at the coin's surface (Fig. 8d), but they cover extremely small areas ( $<20 \mu \mathrm{m}$ in width) (Fig. 8e). However, a second cleaning cycle was not carried out in order to not overclean the surface of the coin. Moreover, EDS analyses have shown very low concentrations of residual chemical elements, diagnostic of the accretions layers (see paragraph 3.3).

The experimental conditions were also tested with several alloys having similar accretions and corrosion products, with the same results, concerning the alloy's protection from heat, the removal of the accretions and corrosion layers and the uniform cleaning result. The
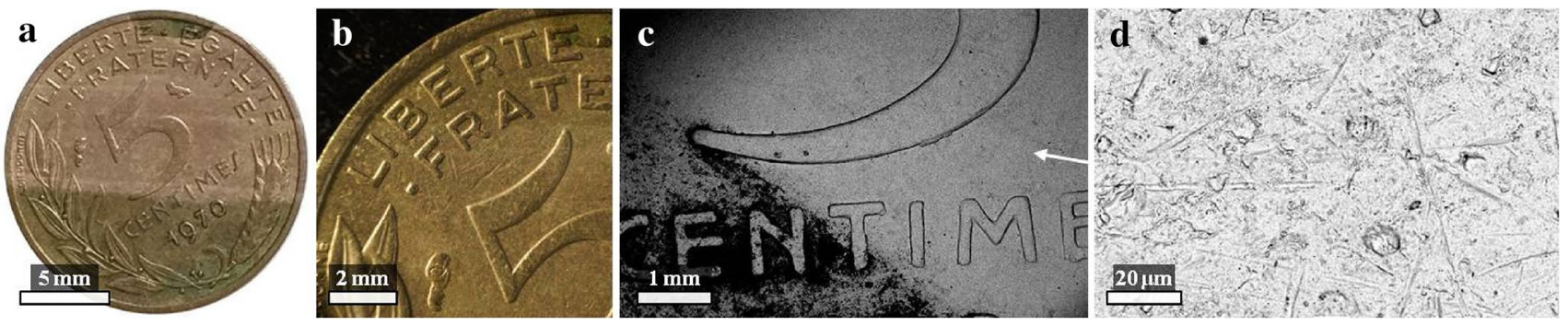

Fig. 6 Optical and electron images of the coin 5_CT: a The upper half represents the cleaned coin, while the bottom half is still corroded. The thin layer of the corrosion allows the observation of the depiction. b OM image of the cleaned area, where the laser evenly remove the corrosion products and the accretions. c SEM image on backscattered mode on the alternation of cleaned and corroded area. d Magnification on the cleaned area, as indicated with the white arrow on image $\mathbf{c}$ 

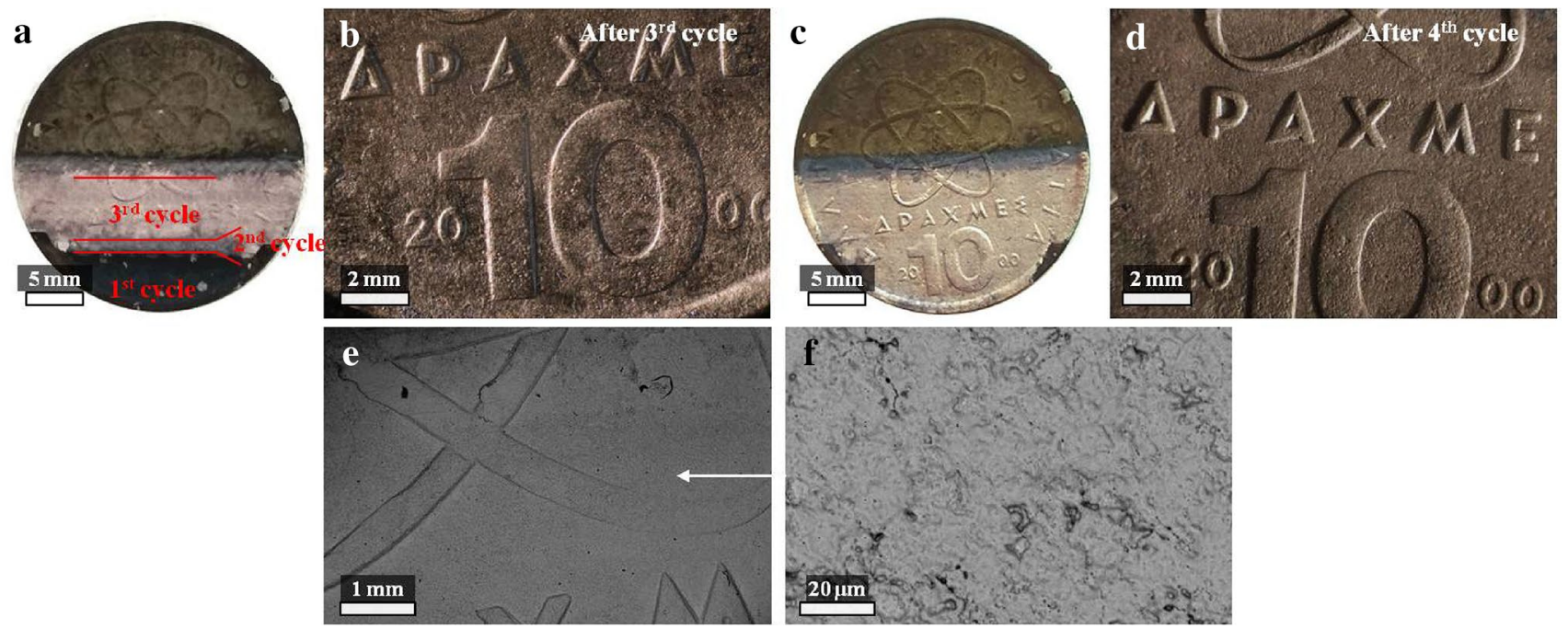

Fig. 7 Coin 10_DR: a optical image with the indications of the first cleaning cycle-black area, the remaining of the second cleaning cycle-purple area, as well as the third cleaning cycle-gray area. b OM image at the end of the third cleaning cycle. c Optical image of the corroded area at the upper half, and the cleaned area at

the bottom half. d OM image of the cleaned area after the fourth cleaning cycle. e SEM image on backscattered mode of a uniformly cleaned area. $\mathbf{f}$ Magnification on the cleaned area, as indicated by the white arrow on image $\mathbf{e}$
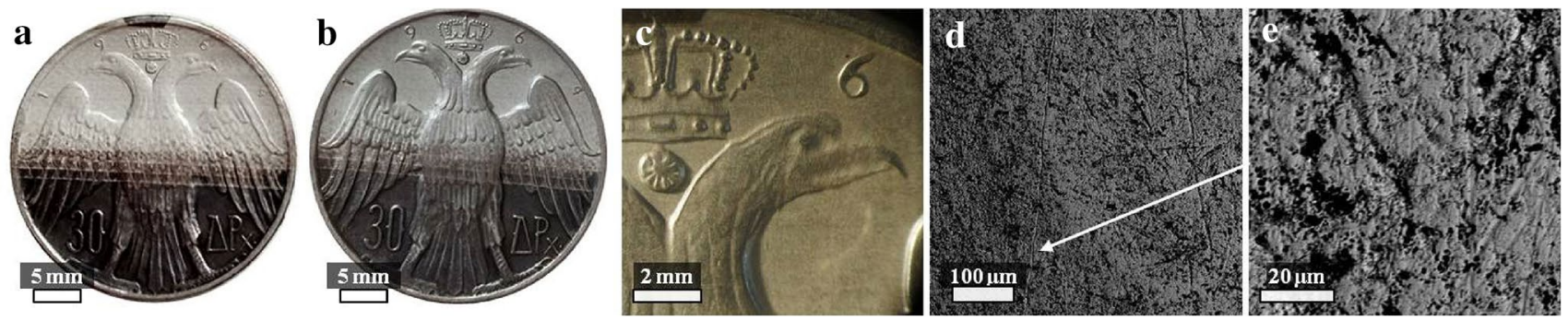

Fig. 8 Coin 30_DR: a optical image after the laser irradiation. b Optical image after wiping the solid silver from the coin's surface. c OM image of the cleaned area. d SEM image on backscattered mode of the cleaned area, with a little remaining of the accretions. e Magnification on the cleaned area, as indicated by the white arrow on image d only required adjustment was in fluence, always ranging between the safe theoretical calculated values, and in the number of the cleaning cycles. Thick layers of accretions required higher fluences than those provided from the developed algorithm and/or more cleaning cycles. It was finally concluded that it is preferable to apply more cleaning cycles with low fluences rather than irradiating with high fluences and less cycles. Higher fluences than the calculated ones were solely applied in the cases that the ablation of the external layers was infeasible otherwise. The cleaning cycles along with OM observation evaluate the process step by step and make the laser cleaning treatment controllable.

\subsection{Evaluation of the cleaning procedure}

After the cleaning procedure, the coins were analyzed with SEM-EDS, in order to chemically compare the cleaned and the corroded areas (Table 4). SEM-EDS is a semiquantitative method. However, the relative elemental concentrations can be useful, especially for alloys, in evaluating the cleaning performance. The alloys are composed of metals; thus, the oxygen is not a part of an alloy and cannot alter the relative concentrations of the rest chemical elements in an analysis. The presence of oxygen as a part of oxides, hydroxides, sulfates, etc. can differentiate the analyzed concentrations. However, for 
Table 4 The elemental concentrations wt. \% of the laser cleaned and corroded areas, compared to the reference concentrations

\begin{tabular}{lllcl}
\hline Coin's name & $\begin{array}{l}\text { Chemi- } \\
\text { cal ele- } \\
\text { ment }\end{array}$ & $\begin{array}{l}\text { Laser } \\
\text { cleaned area } \\
\text { (wt \%) }\end{array}$ & $\begin{array}{l}\text { Corroded } \\
\text { area } \\
\text { (wt \%) }\end{array}$ & $\begin{array}{l}\text { Reference } \\
\text { concentration } \\
\text { (wt \%) }\end{array}$ \\
\hline 10_Dk & $\mathrm{Al}$ & 94.8 & 21.91 & 95 \\
& $\mathrm{Mg}$ & 5.2 & 3.44 & 5 \\
2_DR & $\mathrm{Cu}$ & 100 & 44.4 & 99 \\
& $\mathrm{P}$ & 0 & 5.42 & 1 \\
5_CT & $\mathrm{Cu}$ & 91.75 & 85.21 & 92 \\
& $\mathrm{Al}$ & 5.66 & 9.46 & 6 \\
& $\mathrm{Ni}$ & 2.59 & 2.93 & 2 \\
10_DR & $\mathrm{Cu}$ & 79.87 & 16.10 & 75 \\
& $\mathrm{Ni}$ & 16.37 & 6.72 & 25 \\
30_DR & $\mathrm{Ag}$ & 92.19 & 82.46 & 83.5 \\
& $\mathrm{Cu}$ & 2.67 & 2.37 & 16.5 \\
\hline
\end{tabular}

the alloys, the oxygen presents only on corroded areas (Fig. 9a).

The SEM-EDS spectra of Fig. 9b demonstrate the complete removal of the chemical elements that belong to accretions ( $\mathrm{K}, \mathrm{Na}, \mathrm{Ca}, \mathrm{Si}$, Fe etc.) resulting into cleaned areas. Specifically for the coin 10_Dk, which is composed by an aluminum alloy, the EDS spectrum, before the laser cleaning treatment (Fig. 9a) identifies, besides the aluminum (Al) from the alloy itself, also the elements calcium
(Ca) and silicon ( $\mathrm{Si})$, but also characteristically intense oxygen $(\mathrm{O})$ and carbon $(\mathrm{C})$ peaks. These chemical elements are diagnostic for the existence of calcite $\left(\mathrm{CaCO}_{3}\right)$ and probably anorthite $\left(\mathrm{CaAl}_{2} \mathrm{Si}_{2} \mathrm{O}_{8}\right)$ and also, according to the $\mathrm{XRD}$ analyses, minerals that cover the surface of the coin creating a thick layer of accretions. After the laser cleaning treatment, the accretions have entirely been ablated, as it is demonstrated by the EDS spectrum where only Al and $\mathrm{Mg}$ of the alloy are identified (Fig. 9b) with almost the same concentration with the reference concentration of the coin (Table 4).

Many chemical elements (C, O, Ni, Cu, Mg, Al, Si, P, S, $\mathrm{Cl}, \mathrm{K}, \mathrm{Ca}$ and $\mathrm{Fe}$ ) are also identified on the surface of the coin 2_DR before the laser cleaning treatment. The only mineral, which has been identified from the XRD analysis, is the cuprite $\left(\mathrm{Cu}_{2} \mathrm{O}\right)$, while the rest of the chemical elements are interpreted to belong to traces of silicates, difficult to identify with XRD due to low concentrations on the coin's surface. This coin is visibly covered by corrosion products and accretions, but their layers are thin. After the laser cleaning process, the copper $(\mathrm{Cu})$ is revealed, while the phosphorus $(P)$ from the alloy is not identified (Fig. 9b). The P concentration in the reference composition of the coin is about $1 \mathrm{wt} \%$, a very low value to be considered as an indicator for evaluating the cleaning performance. On the other hand, the complete elimination of oxygen from the coin's surface indicates
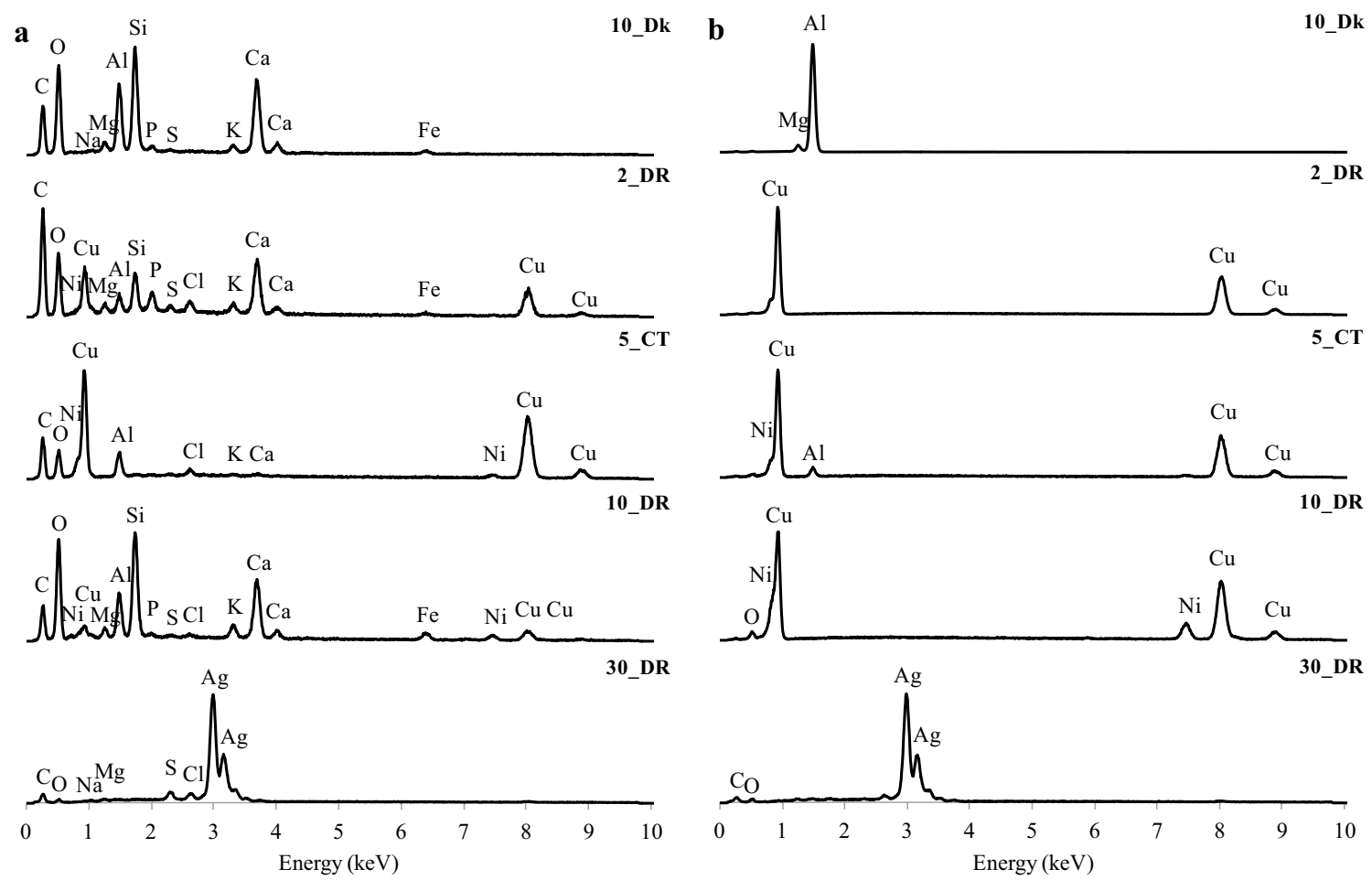

Fig. 9 EDS spectra $\mathbf{a}$ from corroded areas and $\mathbf{b}$ from laser cleaned areas 
full removal of the thin cuprite layer $\left(\mathrm{Cu}_{2} \mathrm{O}\right)$, exposing it to new oxidation processes. Copper alloys are prone to rapid oxidation; thus a layer of patina should remain, in order to preclude continuous corrosion of the deeper layers of the matrix of the alloy. In cases with thin accretions and corrosion layers, it seems to be beneficial for the preservation of the coin, the laser cleaning process to be terminated after the first cleaning cycle.

The coin 5_CT is the one, among the copper-based coins, with the thinnest layers of corrosion and accretions. This can also be reflected on the chemical composition of the corroded area, which shows less divergence from the reference concentration and of the laser cleaned area (Table 4). This is clearly demonstrated by the EDS spectrum (Fig. 9a), in which elements such as C, $\mathrm{O}, \mathrm{Cl}, \mathrm{K}$ and $\mathrm{Ca}$ are fully removed and the alloy is revealed showing the reference chemistry, consisting of $\mathrm{Cu}, \mathrm{Al}$ and $\mathrm{Ni}$. Traces of oxygen (Fig. $9 \mathrm{~b}$ ) dictate that a small cuprite layer is intentionally preserved.

The coin 10_DR was severely corroded. Its alloy was entirely covered by thick layers of corrosion products and accretions, which are clearly demonstrated in the EDS spectrum (Fig. 9a). In this spectrum, only the elements of the accretions layers are observed (C, O, Al, Si, $\mathrm{Ca}$ ) almost totally masking the chemical elements of the alloy $(\mathrm{Cu}, \mathrm{Ni})$. After the laser cleaning process, the elements of the alloy are fully revealed with concentration of $\mathrm{Cu}=79.87 \mathrm{wt} \%$ and $\mathrm{Ni}=16.37 \mathrm{wt} \%$ that approach the reference concentration ( $\mathrm{Cu}=75 \mathrm{wt} \%, \mathrm{Ni}=25 \mathrm{wt} \%)$. The divergence is due to the cuprite layer that still remains on the surface of the coin, of which oxygen changes the absolute and relative concentrations of the cleaned surface. Further minimization of the cuprite layer was not an option because of the already strong corrosion, visible as intense roughness of the surface of the coin, which already affects the details of the coin's engravings.

The silver-based coin 30_DR is the only in which the silver percentage (in wt\%) is larger than the reference value (Table 4). This is probably due to remaining metallic silver, which is still covering the alloys' matrix, because it was not fully wiped from the coin's surface. Furthermore, it is the only coin in which accretions $(\mathrm{Mg}, \mathrm{Al}, \mathrm{Si})$ still remain with a small percentage of $\sim 1 \mathrm{wt} \%$ each, as analyzed with EDS, in several areas on the surface of the coin. Sulfur, mainly as a part of the corrosion product silver sulfide, also remains at the cleaned areas, but its concentration was decreased from $6.7 \mathrm{wt} \%$ at the corroded areas, to $0.9 \mathrm{wt} \%$, because sulfur's main source has possibly been decomposed to solid silver due to the laser irradiation. The low concentrations of the corrosion products and the accretions are represented in the EDS spectrum but with difficulty due to peaks with very low intensity (Fig. 9b).

\section{Conclusions}

The composition of the alloys of each coin that has been studied here, as well as the thickness of the corrosion products and that of the accretions layers, clearly affected the parameters used for the laser treatment of the coins at $1064 \mathrm{~nm}$ wavelength. This research shows that the laser cleaning treatment with a Q-switched Nd:YAG laser (1064 nm, $6 \mathrm{~ns}$ ) is possible for aluminum- , copper- , and silver-based alloys. The minimum fluence, which is interacting with the accretions and corrosion layers, is beneficial to be used, for protecting the alloy from excess energy.

Moreover, the application of a water film before the laser cleaning procedure was proven necessary solely for copper-rich alloys ( $\mathrm{Cu}>95 \mathrm{wt} \%)$. The application of a final cleaning cycle with very low fluence and large spot size is required for the laser cleaning treatment of copper-aluminum alloys and aims to a uniform cleaning result. The silver-based alloys, which are covered by corrosion products such as the silver sulfide, can be cleaned with low fluences, but mechanical cleaning is required as well, for the completion of the cleaning procedure. The composition of the corrosion products dictates this procedure.

The thickness of the accretions and corrosion layers also affects the cleaning treatment, and it is totally independent of the composition of the alloy. Higher values of fluences were used on aluminum and copper-nickel alloys to remove thick accretions layers and simultaneously protect the alloy by selectively and controllably irradiating these areas.

A theoretical model of the heat transfer to the material during cleaning was developed in order to constrain the range of fluences during the experiments, in order to protect the alloy's matrix. The algorithm that was developed is easy to use and requires only the relevant constants (physical, optical and thermal) of the analyzed material, as well as that of the laser parameters (energy intensity and pulse duration). The minimum fluence required to induce phase changes in each alloy is calculated, as well as a temperature profile during the irradiation. These calculations can only be considered as approximations, and they can be used as a safe range of values for laser cleaning tests. They successfully apply to a small subset of coin alloys used for this study and its preliminary experiments, with the potential to be used for the complete set of alloy compositions of the extended set of coins, after a systematic work. Completing the dataset of compositions would also allow the development of semiautomated cleaning procedures. Moreover, the instrument setup fully controlled by in-house software and assisted by visual inspection could be the basis for manufacturing a commercial semi-automated laser cleaning system. 


\section{Compliance with ethical standards}

Conflict of interest On behalf of all authors, the corresponding author states that there is no conflict of interest.

\section{References}

1. Veiko VP, Mutin TJ, Smirnov VN, Shakhno EA, Batishche SA (2008) Laser cleaning of metal surfaces: physical processes and applications. In: Fundamentals of laser assisted micro-and nanotechnologies, vol 6985. International Society for Optics and Photonics, p. 69850D

2. Salimbeni R (2006) Laser techniques for conservation of artworks. Archeometriai Mühely 3(1):34-40

3. Siano S, Agresti J, Cacciari I, Ciofini D, Mascalchi M, Osticioli I, Mencaglia AA (2012) Laser cleaning in conservation of stone, metal, and painted artifacts: state of the art and new insights on the use of the Nd:YAG lasers. Appl Phys A 106:419-446

4. Zanini A, Trafeli V, Bartoli L (2018) In IOP conference series materials science and engineering, $\mathrm{p} 12078$

5. Abdel-Kareem O, Al-Zahrani A, Khedr A, Harith MA (2016) Evaluating the use of laser in analysis and cleaning of the Islamic marine archaeological coins excavated from the red sea. Int J Conserv Sci 7:511

6. Zhu H, Lu J, Ni X, Shen Z (2017) Experimental investigation on cleaning of corroded ancient coins using a Nd:YAG laser. In: Fourth international symposium on laser interaction with matter, vol 10173. International Society for Optics and Photonics, $p$ $101730 \mathrm{~F}$

7. Drakaki E, Klingenberg B, Serafetinides AA, Kontou E, Katsikosta N, Tselekas P, Evgenidou D, Boukos N, Zanini A (2010) Evaluation of laser cleaning of ancient Greek, Roman and Byzantine coins. Surf Interface Anal 42:671-674

8. Korenberg C, Baldwin A (2006) Laser cleaning tests on archaeological copper alloys using an ND:YAG laser. Laser Chem 2006:1-7

9. Moreno-Suárez Al, Ager FJ, Rodríquez-Segovia C, Gómez-Morón A, Chaves F, Scrivano S, Gómez-Tubío B, Pliego R, Respaldiza MA (2015) Feasibility of different cleaning methods for silver-copper alloys by X-ray fluorescence: application to ancient Greek silver coins. Spectrochim Acta Part B At Spectrosc 116:85-91. https:// doi.org/10.1016/j.sab.2015.11.007

10. Palomar T, Ramírez Barat B, García E, Cano E (2015) A comparative study of cleaning methods for tarnished silver. J Cult Herit 17:20-26

11. Antonopoulou-Athera N, Chatzitheodoridis E, Christodoulopoulos Z, Evangelatos C, Serafetinides A, Zekou E (2013) Vol 2, session $B$ diagnostic, restoration conservation 6th international congress science and technology safeguard cultural heritage mediterranean basin (Athens, 2013), pp 403-410

12. Drakaki E, Kandyla M, Chatzitheodoridis E, Zergioti I, Serafetinides AA, Terlixi A, Kouloumpi E, Moutsatsou AP, Doulgerides M, Kantarelou V, Karydas A, Vlachou-Mogire C (2010) Laser studies of metallic artworks. Appl Phys A Mater Sci Process 101:349-355

13. Korenberg C, Baldwin AM, Pouli P (2008) Lasers conservation artworks, edited by M. Castillejo, P. Moreno, M. Oujja, R. Radvan, and J. Ruiz. Taylor \& Francis Group, London, pp 285-290
14. Ibrahim HI, Hamoudi WK, Edan MS (2016) Nanosecond Nd:YAG laser surface cleaning of metals and marbles. Iraqi J Laser $14: 21-26$

15. Fotakis C, Anglos D, Zafiropulos V, Georgiou S, Tornari V (2007) Lasers in the preservation of cultural heritage. Taylor \& Francis Group, London

16. Cuhaj G (ed) (2010) 2010 Standard catalog of world coins 19012000,37 th edn. Krause publications, lola

17. Landolt $D$ (2007) Corrosion and surface chemistry of metals. EPFL Press

18. Montoya N, Montagna E, Lee Y, Doménech-Carbó MT, Doménech-Carbó A (2017) Raman spectroscopy characterization of 10 -cash productions from the late $C$ hinese emperors to the $R$ epublic. J Raman Spectrosc 48:1337-1345

19. Martina I, Wiesinger $R$, Jembrih-Simburger $D$, Schreiner $M(2012)$ Micro-Raman characterisation of silver corrosion products: instrumental set up and reference database. E-Preserv Sci 9:1-8

20. Blackwell BF (1990) Temperature profile in semi-infinite body with exponential source and convective boundary condition. J Heat Transf 112:567-571

21. Sands D (2011) Pulsed laser heating and melting. In: Heat transfer-engineering applications. InTech

22. Yilbas BS, Shuja SZ (1997) Heat transfer analysis of laser heated surfaces-conduction limited case. Appl Surf Sci 108:167-175

23. Yilbas BS, Shuja SZ (1999) Laser short-pulse heating of surfaces. J Phys D Appl Phys 32:1947-1954

24. Wood RM (2003) Laser-induced damage of optical materials, series in optics and optoelectronics, 1 st edn. Institute of Physics Publishing, Bristol

25. Touloukian Y (1970) Thermophysical properties of matter-the TPRC data series. IFI/Plenum, New York

26. Klemens $P$ (1976) Thermal conductivity, vol 14. Springer, Boston

27. Chase MW Jr, Davies CA, Downey JR Jr, Frurip DJ, McDonald RA, Syverud AN (1986) JANAF thermochemical tables, 3rd edn. U.S. Department of Commerce on Behalf United States (1986)

28. Cardarelli F (2008) Materials handbook a concise desktop reference, 2nd edn. Springer, London

29. Parker WJ, Jenkins RJ, Butler CP, Abbott GL (1961) Flash method of determining thermal diffusivity, heat capacity, and thermal conductivity. J Appl Phys 32:1679-1684

30. Perry DL (2011) Handbook of inorganic compounds, 2nd edn. CRC Press, Boca Raton

31. Ito T, Kawashima T, Yamaguchi H, Masumi T, Adachi S (1998) Optical properties of Cu $2 \mathrm{O}$ studied by spectroscopic ellipsometry. J Phys Soc Jpn 67:2125-2131

32. Querry M (1985) Optical constants. University of Missouri, Kansas City

33. Bennett JM, Stanford JL, Ashley EJ (1970) Optical constants of silver sulfide tarnish films. J. Opt. Soc. Am. 60:224-232

34. Adams DP, Goeke RS, Sobczak CS, Jones EDJ, Rodriguez M (2012) AVS NM chapter symposium

35. Froidevaux $M$, Platt $P$, Cooper $M$, Watkins $K$ (2008) Lasers conservation of artworks, edited by M. Castillejo, P. Moreno, M. Oujja, R. Radvan, and J. Ruiz. Taylor \& Francis Group, London, pp 277-284

Publisher's Note Springer Nature remains neutral with regard to jurisdictional claims in published maps and institutional affiliations. 